\title{
Germline genes hypomethylation and expression define a molecular signature in peripheral blood of ICF patients: implications for diagnosis and etiology
}

Guillaume Velasco ${ }^{* *}$, Emma L Walton ${ }^{1}$, Delphine Sterlin², Sabrine Hédouin ${ }^{1}$, Hirohisa Nitta ${ }^{5}$, Yuya Ito ${ }^{5}$, Fanny Fouyssac ${ }^{6}$, André Mégarbané ${ }^{7}$, Hiroyuki Sasaki ${ }^{5}$, Capucine Picard ${ }^{2,3,4}$ and Claire Francastel $^{1^{*}}$

\begin{abstract}
Background: Immunodeficiency Centromeric Instability and Facial anomalies (ICF) is a rare autosomal recessive disease characterized by reduction in serum immunoglobulins with severe recurrent infections, facial dysmorphism, and more variable symptoms including mental retardation. ICF is directly related to a genomic methylation defect that mainly affects juxtacentromeric heterochromatin regions of certain chromosomes, leading to chromosomal rearrangements that constitute a hallmark of this syndrome upon cytogenetic testing. Mutations in the de novo DNA methyltransferase DNMT3B, the protein ZBTB24 of unknown function, or loci that remain to be identified, lie at its origin. Despite unifying features, common or distinguishing molecular signatures are still missing for this disease.

Method: We used the molecular signature that we identified in a mouse model for ICF1 to establish transcriptional biomarkers to facilitate diagnosis and understanding of etiology of the disease. We assayed the expression and methylation status of a set of genes whose expression is normally restricted to germ cells, directly in whole blood samples and epithelial cells of ICF patients.

Results: We report that DNA hypomethylation and expression of MAEL and SYCE1 represent robust biomarkers, easily testable directly from uncultured cells to diagnose the most prevalent sub-type of the syndrome. In addition, we identified the first unifying molecular signatures for ICF patients. Of importance, we validated the use of our biomarkers to diagnose a baby born to a family with a sick child. Finally, our analysis revealed unsuspected complex molecular signatures in two ICF patients suggestive of a novel genetic etiology for the disease.

Conclusions: Early diagnosis of ICF syndrome is crucial since early immunoglobulin supplementation can improve the course of disease. However, ICF is probably underdiagnosed, especially in patients that present with incomplete phenotype or born to families with no affected relatives. The specific and robust biomarkers identified in this study could be introduced into routine clinical immunology or neurology departments to facilitate testing of patients with suspected ICF syndrome. In addition, as exemplified by two patients with a combination of molecular defects never described before, our data support the search for new types of mutations at the origin of ICF syndrome.
\end{abstract}

Keywords: Agammaglobulinemia, DNA methylation, Heterochromatin, DNA, Satellite, Gene expression, Biological markers/diagnosis use, Biological markers/etiology, Genes, X-linked

\footnotetext{
*Correspondence: guillaume.velasco@univ-paris-diderot.fr; claire.francastel@

univ-paris-diderot.fr

'Université Paris Diderot-Paris7, CNRS UMR7216, Epigénétique et Destin Cellulaire, Case Courrier 7042; 35, rue Hélène Brion, 75205 Paris, France

Full list of author information is available at the end of the article
} 


\section{Background}

Immunodeficiency with centromeric instability and facial anomalies (ICF; OMIM no. 242860) is a rare autosomal recessive disorder mainly characterized by primary immunodeficiency [1]. Recurrent infections are the presenting symptom, usually in early childhood. Other features include mild facial anomalies and variable symptoms including intellectual disability, congenital malformations and developmental delay [2].

ICF syndrome is a genetically heterogeneous disease with heterogeneous molecular defects and phenotypic variability (Reviewed in [3]). Around 60\% of patients (ICF1) have mutations in the catalytic domain of the de novo DNA methyltransferase (DNMT) DNMT3B [4-6] leading to reduced enzymatic activity $[7,8]$ associated with a significant loss of DNA methylation, notably at juxtacentromeric satellite repeats on chromosome 1 and 16, and less frequently 9 (Reviewed in [9]). The remainder have either non-sense mutations in the zinc-finger and BTB domain-containing 24 (ZBTB24) gene (ICF2) [10] or no identifiable mutation in either DNMT3B or ZBTB24 coding sequences (ICFX) [11]; both ICF2 and ICFX show hypomethylation of centromeric alpha-satellites ( $\alpha$-Sat) in addition to the above mentioned repeats [12]. Hypomethylation of satellite repeats is associated with centromeric instability and constitutes an invariant molecular hallmark of ICF patients. Chromosomal anomalies are detectable by karyotype analysis of mitogenstimulated lymphocytes and that is used to establish the diagnosis $[13,14]$.

Data obtained in ICF lymphoblastoid cell lines (LCLs) showed that DNMT3B mutations also lead to hypomethylation and perturbed expression of several hundred of genes involved in immune function, development and neurogenesis, being both up- and down-regulated, which probably account for the phenotypical manifestations documented in patients [15-17]. Additional molecular mechanisms acting in trans, such as perturbed nuclear organization as a result of the altered juxtacentromeric or telomeric heterochromatin organization [18-20], deregulated expression of small regulatory microRNAs (miRNA) [21] or changes in replication timing [22] may also have a deep impact on the deregulation of gene expression programs in ICF patients. However, these perturbed profiles showed great variability, probably reflecting phenotypic variability between patients and cell culture effects, and no common or distinguishing molecular signatures could be reliably established from these studies.

Our analysis of perturbed DNA methylation patterns and expression programs in a mouse model for ICF1 revealed the striking over-representation of germline genes among the most upregulated genes [23]. In addition, our data suggested a new role for Dnmt3b in the protection of somatic cells against the promiscuous expression of the germ line program, playing the central role in both the establishment and maintenance of DNA methylation profiles at these genes [24]. Although the impact of their illicit expression on ICF phenotypes remains to be solved, their inherent repressed state in all somatic cells makes them good candidate biomarkers of molecular dysfunctions in ICF syndrome. We tested hypomethylation and illicit expression of the thus identified germline genes in a cohort of ICF patients that included five newly enrolled patients, in order to establish a molecular signature easily testable directly from the blood of ICF patients.

\section{Material and methods}

This study was conducted in accordance with the Helsinki Declaration, with informed consent obtained from each patient or the patient's family. The study was approved by the local ethics committee of Necker-Enfants Malades Hospital, Paris, France.

An expanded Methods section for DNA methylation and gene expression analysis can be found in Additional file 1.

\section{Healthy donors and patients}

Blood samples of six healthy volunteers, aged 35, 24, 26, 27, 29 and 41 years, respectively, were collected and were numbered from 1 to 6 . Donors 3 and 6 are women.

Our cohort of patients included thirteen ICF1 patients with mutations in DNMT3B, six ICF2 patients with mutations in ZBTB24 and four ICFX patients with as of yet unknown mutations (Additional file 2). Most patients were described earlier [11,12,25-27] except for five newly enrolled patients (Table 1 ). The ICF B-lymphoblastoid and fibroblasts named here pCor were obtained from the Coriell Cell Repositories (USA) (http://ccr.coriell.org/). Patients pG, pR, pI, pH, pC, pD, pN, pP, pS were recruited by the ICF Consortium and described together with patients pG, pR, pI, pH, pC, pD, pN, pP, pS in [12]. Patients pW, pT and P5 were described earlier $[11,25,26]$. Patients P7 and P8 were recently classified as ICF2 patients [27]. Patients $\mathrm{pC}, \mathrm{pS}, \mathrm{pU}$ and $\mathrm{pN}$ were classified as ICFX patients since sequence analysis of DNMT3B and ZBTB24 genes performed as previously described [12,27] did not reveal any mutation in their coding sequences.

New ICF syndrome patients P1, P2, P3, P4 and pY were diagnosed according to cytogenetic analysis that revealed typical multiradial chromosome configurations with multiple arms from chromosomes 1 and 16, and clinical features, mainly primary immunodeficiency. For these patients, primary immunodeficiency and hypomethylation at satellite repeats are detailed in Additional files 3 and 4 . These patients were classified as ICF1 patients (Necker Hospital, Paris, France) based on mutations found in DNMT3B using previously described sequencing methods [12,27]. Written informed consent was obtained from the parents of the patients. 
Table 1 Genetic characteristics of newly identified ICF1 patients

\begin{tabular}{lccccc}
\hline Patients & P1 & P2 & P3 $^{*}$ & P4 $^{*}$ & pY \\
\hline Year of birth & 2010 & 2008 & 2009 & 2013 & 1996 \\
Gender & F & M & F & F & M \\
Amino acid changes in DNMT3B (NP_008823.1) & p. S655L/? & p. R104X/p. I721T & p. G583S/p. G583S & p. G583S/p. G583S & p.T7751/p.T7751 \\
Consanguinity & NO & NO & YES & YES & YES \\
\hline
\end{tabular}

M: male; F: female; *siblings.

\section{Primary cells and cell lines}

Primary fibroblasts (passage 7 for $\mathrm{pG}, \mathrm{pW}$ and $\mathrm{pT}$; passage 5 for pR; passage 6 for pI; passage 14 for $\mathrm{pC}$ and $\mathrm{pP}$; passage 9 for pCor and pS) and Lymphoblastoid cell lines (LCLs) from healthy donors and ICF patients were cultured in DMEM and RPMI 1640 respectively, supplemented with 15\% FCS, glutamine and antibiotics (Invitrogen).

Methylation-sensitive restriction enzyme-coupled qPCR assay Genomic DNA (200 ng) was digested at $37^{\circ} \mathrm{C}$ for $4 \mathrm{~h}$ with $10 \mathrm{U}$ of the methylation-sensitive enzyme Acil, or NcoI (New England Biolabs) which does not have cutting sites in our regions of interest and served to normalize the data. The endonucleases were subsequently inactivated by incubation at $65^{\circ} \mathrm{C}$ for $20 \mathrm{~min}$. Real-time PCR was carried out using the light cycler-DNA MasterPLUS SYBR Green I mix (Roche) supplemented with $0.5 \mu \mathrm{M}$ specific primer pairs and with $2 \mu \mathrm{L}$ of digested DNA. Real-time quantification PCR were run on a light cycler rapid thermal system (LightCycler ${ }^{\circ} 480$ 2.0 Real time PCR system, Roche) with $20 \mathrm{sec}$ of denaturation at $95^{\circ} \mathrm{C}$, $20 \mathrm{sec}$ of annealing at $65^{\circ} \mathrm{C}$ and $20 \mathrm{sec}$ of extension at $72^{\circ} \mathrm{C}$ for all primers, and analyzed by the comparative CT $(\triangle \mathrm{CT})$ method according to the formula: methylation $(\%)=E^{(\Delta C T)} \times 100$ where $E$ represents PCR efficiency and $\Delta \mathrm{CT}=\mathrm{CT}_{\text {sample }}$ (Acil digest) $-\mathrm{CT}_{\text {sample }}$ (NcoI digest). Sequences of primers within $\mathrm{CpG}$ islands at germline gene promoters are shown in Additional file 1. Each data shown on histograms is the mean result of qPCR analysis on at least three independent experiments performed on at least three independent genomic extractions.

\section{Results and discussion}

Hypomethylation and expression of MAEL and SYCE1 define molecular markers for ICF1 syndrome

Peripheral blood samples were obtained from healthy donors and ICF patients. We assessed profiles of gene expression focusing on the germline genes transcriptional signature that we previously established in a mouse model for ICF1 [23,24].

As expected from their expression primarily in germ cells (Additional file 5; and RNAseq and exon arrays datasets on normal tissues publically available at UCSC genome browser) and function in meiosis, expression of the germline genes tested was undetectable in blood cells from healthy controls, although that of SYCE1 showed some degree of variation between healthy donors that did not seem to correlate with age or sex (Figure 1 and Additional file 6). In contrast, strong expression was detected for two of them in blood cells from ICF patients; among all the germline genes tested, only that of MAELSTROM (MAEL), involved in repression of transposable elements during meiosis, and Synaptonemal Complex Central Element Protein 1 (SYCE1), involved in assembly of the synaptonemal complex during meiosis in germ cells, were transcribed in blood cells from ICF patients (Figure 1 and Additional files 6 and 7). This illegitimate expression in whole blood was very strong and remarkably specific for ICF1 patients while at significantly lower levels in ICF2 blood cells (raw data and p values in Additional file 6). Interestingly, patient P5 had only mild ICF phenotype [25] although he showed strong expression of $M A E L$ and SYCE1. Therefore, given their repressed state in normal somatic tissues, detection of MAEL and SYCE1 expression in blood cells provides a statistically significant signature for the most prevalent sub-type of the disease, regardless of the severity of the symptoms.

Since the germline genes tested in this study are known to be repressed through DNA methylation in mice $[23,24,28]$ we analyzed their methylation status on genomic DNA isolated from fresh whole blood samples (Figure 2A) or epithelial cells obtained from buccal swabs (Figure 2B), from ICF patients and healthy donors. Consistent with their expression only in blood cells from ICF1 patients (Figure 1), analysis of methylation at MAEL and SYCE1 revealed their hypomethylated state specifically in ICF1 patients since ICF2 and ICFX patients (except ICFX patient pN; discussed below) were methylated at values comparable to healthy controls (raw data and p values in Additional file 8). Similarly, Solute Carrier family 25 member 31 (SLC25A31 also known as ANT4), encoding a mitochondrial ADP/ATP carrier essential during spermatogenesis, was significantly hypomethylated only in ICF1 patients (Figure 2 and Additional file 8) although this hypomethylation did not correlate with transcriptional activation (Additional file 6).

Importantly, and as mentioned above, this transcriptional signature could not have been unraveled using classically available cultured patient cells like Epstein-Barr virustransformed lymphoblastoid cell lines (LCLs) and primary fibroblasts. Indeed, although we could easily detect MAEL 


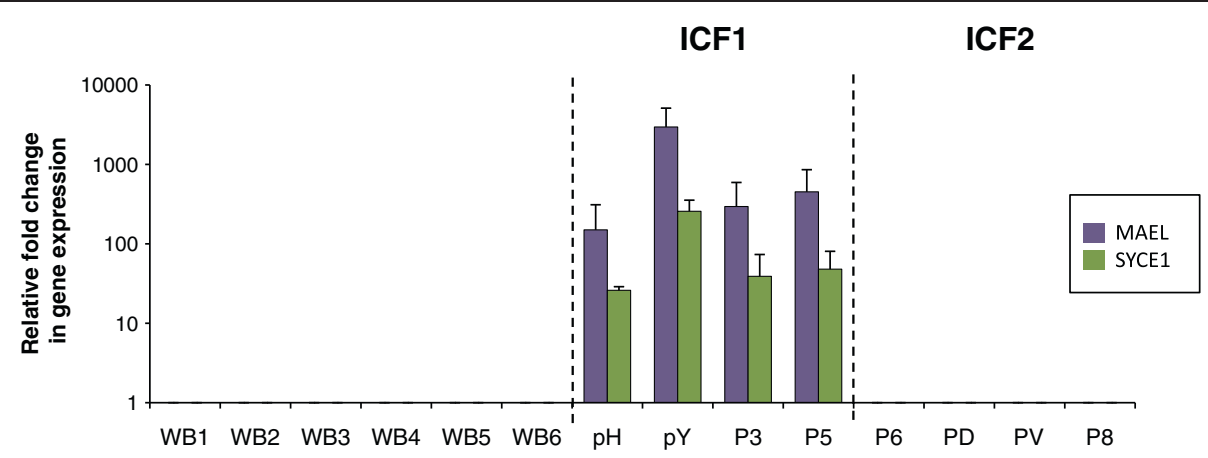

Figure 1 Expression of MAEL and SYCE1 in whole blood defines specific biomarkers for ICF1 patients. Expression levels of MAEL (purple bars) and SYCE1 (green bars) were assessed by qRT-PCR, normalized to U6 snRNA levels and presented as fold change relative to that of control whole blood from healthy donors (WB). ICF subtypes 1 and 2 are indicated and separated by dotted lines. Raw data used to built this Figure can be found in Additional file 6. WB, control whole blood from healthy donors. Error bars represent standard error.

and SYCE1 transcripts in these cultured cells, this expression was independent of patient genotype (Additional file 7). We also noticed that the illicit expression of $M A E L$ in fibroblasts from ICF1 patients became undetectable beyond passage 9 (Additional file 9), although DNA methylation levels at its promoter remained relatively unchanged, suggesting that extensive culture may limit findings of illegitimately expressed genes. Hypomethylation of DNMT3B-target genes in ICF2 and ICFX cells (Additional file 7), in which DNMT3B is not mutated, could result from well-known, direct or indirect, aberrant culture-induced defects of DNA methylation [29]. Furthermore, EBV transformation and cell culture perturb DNA methylation patterns in human LCLs, in particular at satellite repeats of juxtacentromeric regions [30] that are used to diagnose ICF patients. Therefore, like in previously reported transcriptomic studies examining differential gene expression profiles between ICF patients and healthy controls $[15,16]$, our data obtained in LCLs or fibroblasts probably reflected culture-associated defects in DNA methylation and gene expression, which have been superimposed on the intrinsic defects that affect patients, and do not allow the reliable identification of biomarkers with diagnostic value.

In contrast, the analysis that we conducted in uncultured cells from patients provided the first blood-based gene expression test to identify ICF1 syndrome, and the first discriminating transcriptional differences amongst ICF patients. The molecular functions of ZBTB24 remain to be identified, but the finding that the germline genes tested herein are not similarly affected by mutations in DNMT3B or ZBTB24 contradicts earlier suggestion that ZBTB24 is a mere adapter of DNMT3B function [12].

\section{Hypomethylation signature common to patients with mutations in DNMT3B or ZBTB24}

DNA methylation at the promoters of DEAD (Asp-GluAla-Asp) Box Polypeptide 4 (DDX4), the homolog of
VASA proteins in Drosophila with key roles in germ cells development, and Testis Expressed 12 (TEX12), was similar between patients and controls, suggesting that, in contrast to the mouse, methylation of these genes was not affected in human DNMT3B- or ZBTB24-deficient cells (Additional file 10). Interestingly, the Synaptonemal Complex Protein 1 (SYCP1) gene showed significant hypomethylation in all but one ICFX patient with unknown mutation. Similarly, we observed hypomethylation of the $\mathrm{X}$-linked testis-expressed gene 11 (TEX11) irrespective of ICF subtype (Figure 2; black bars), but restricted to female ICF cells (raw data and $\mathrm{p}$ values in Additional file 8). Whether hypomethylation at SYCP1 and TEX11 promoters was a direct consequence of ZBTB24 loss of integrity remains to be seen. However, these data identifies SYCP1 and TEX11 as the first unique gene loci affected by ZBTB24 mutations and contribute to a significant progress in our understanding of the etiology of ICF syndrome. In the case of the X-linked gene TEX11, it is likely related to the global hypomethylation of the inactive $\mathrm{X}$-chromosome reported in female ICF1 patients [31,32]. Therefore, the hypomethylation of SYCP1 and TEX11 (Figure 2 and Additional file 8) regardless of the ICF subtype represents the first unifying molecular signature for ICF syndrome and suggests that hypomethylation of the inactive $\mathrm{X}$-chromosome in female patients may represent an invariant feature of ICF syndrome. In addition, these data point to a putative role of ZBTB24 in establishment or maintenance of DNA methylation at the inactive $\mathrm{X}$-chromosome.

\section{A new molecular heterogeneity among ICF patients}

The perturbations that we reported here represent a reliable index of DNMT3B dysfunction in ICF1 patients, with the notable exception of patient $\mathrm{pN}$. Based on our predictions of a molecular signature that varies according to ICF genotype, the germline methylation (Figure 2) and expression (Figure 1) signatures that we found in 

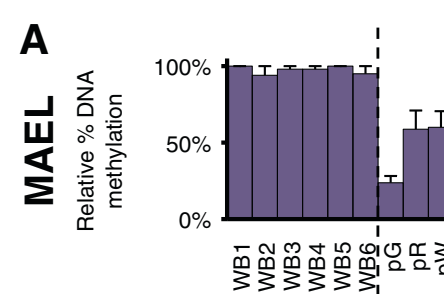

\section{1}
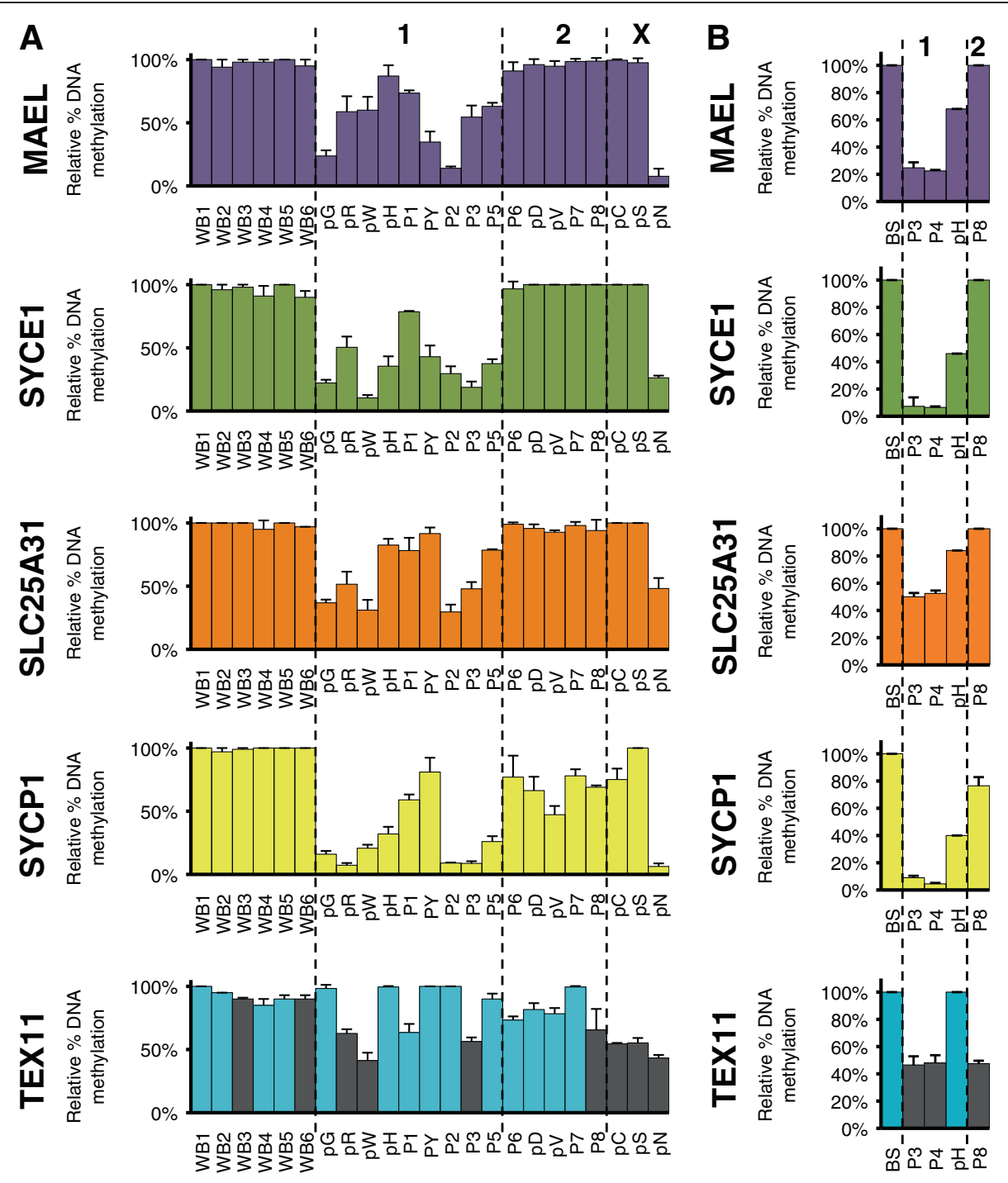

Figure 2 Relative DNA methylation levels at germline gene promoters in whole blood and buccal swabs from ICF patients. Methylation analysis in whole blood (A) and buccal swabs (B) were assessed by Methylation-Sensitive Restriction Assay, followed by qRT-PCR amplification of the Acil digested product with primers flanking at least two Acil sites within the promoter CpG island. A non-cutter Ncol control digest served to normalize data that are presented as a percentage of methylation relative to the control digest. ICF subtypes 1, 2, and X are indicated and separated by dotted lines. For the X-linked gene TEX11, female patients are indicated as black bars. Raw data used to built this Figure can be found in Additional file 8. WB and BS are control whole blood DNA and buccal swabs from healthy donor, respectively. Error bars represent standard error.

ICFX patient $\mathrm{pN}$ would place this patient in the ICF1 subtype. However, no mutation was previously found in the coding regions of DNMT3B for this patient [12] or in a new sequencing of DNMT3B and ZBTB24 exons. Intriguingly, the ICFX patient $\mathrm{pN}$ differs from other ICFX patients in that this patient had some degree of hypomethylation at $\alpha$-Sat repeats, intermediate between hypomethylation found in ICF2 cells and almost full methylation characteristic of normal and ICF1 cells (Additional file 4). In addition, this profile resembles that of patient $\mathrm{P} 1$, first classified as ICF1 because of mutations in DNMT3B maternal allele but for whom no mutation could be found in the coding regions of the paternal allele. The combination of hypomethylation at MAEL and SYCE1 germline genes, indicative of DNMT3B impaired activity, with modest but reproducible hypomethylation at $\alpha$-Sat repeats, which is never observed in ICF1 patients and was instrumental in suggesting genetic heterogeneity among ICF patients, implies an even more complex genetic etiology for these two patients. In the absence of an identified "culprit gene" for these patients, it remains unclear whether a third locus is implicated in ICF syndrome. Alternatively, these patients could be "compound" heterozygotes for mutations in both $D N M T 3 B$ and ZBTB24, though it would have to be outside coding regions since exome sequencing did not reveal any mutation in the exons of any of the two genes. The 
genetic defects in these patients will be probably highly informative from a mechanistic perspective regarding the establishment and maintenance of DNA methylation patterns. These observations also emphasize that additional molecular markers besides the methylation of $\alpha$-Sat sequences are required to distinguish various classes of ICF patients.

\section{Expression and methylation of germline genes to diagnose individuals with suspected ICF syndrome}

We propose that profiling of DNA methylation at $M A E L$ and SYCE1 germline genes, combined to the detection of their illicit expression using non-invasive diagnostic techniques, could serve as a powerful, quick, and simple procedure to diagnose patients with suspected ICF1 syndrome. Because these genes are normally repressed in somatic tissues, any diagnostic test based on their expression will give an unambiguous result. To test the power of these genes for diagnostic means, we assessed methylation and expression profiles of germline genes in a child born to a consanguineous family but whose genotype at the time of testing was not known. This child, who is a sibling of patient P3, was born during the course of this study, and we were able to sample buccal epithelial cells and peripheral blood when she was 3 months old. Our analysis revealed germline gene methylation and transcription profiles typical of that of ICF1 patients tested in this study (Figure 3 and p values in Additional file 8). These observations were highly suggestive of the ICF1 syndrome in this child, who we named patient P4 (Table 1). In line with our predictions, diagnosis of the ICF1 syndrome was subsequently confirmed by sequencing of DNMT3B exons and characterization of the same mutations identified in her older sister (Table 1).

\section{Conclusions}

Correlations between genotype and phenotype of ICF patients are emerging [11], and the defining of a reliable ICF-specific molecular signatures will help to explain such differences in the clinical manifestations of ICF syndrome amongst ICF patient subtypes. In addition to providing a new contribution to the characterization of unifying and distinguishing molecular signatures between ICF patient subtypes, this first molecular signature identifiable in the peripheral blood or epithelial cells of patients could be easily introduced into routine clinical immunology or neurology departments to facilitate testing of patients with suspected ICF syndrome. Because ICF is probably underdiagnosed, we predict that the analysis of such markers will greatly aid diagnosis and prioritize patients for mutation

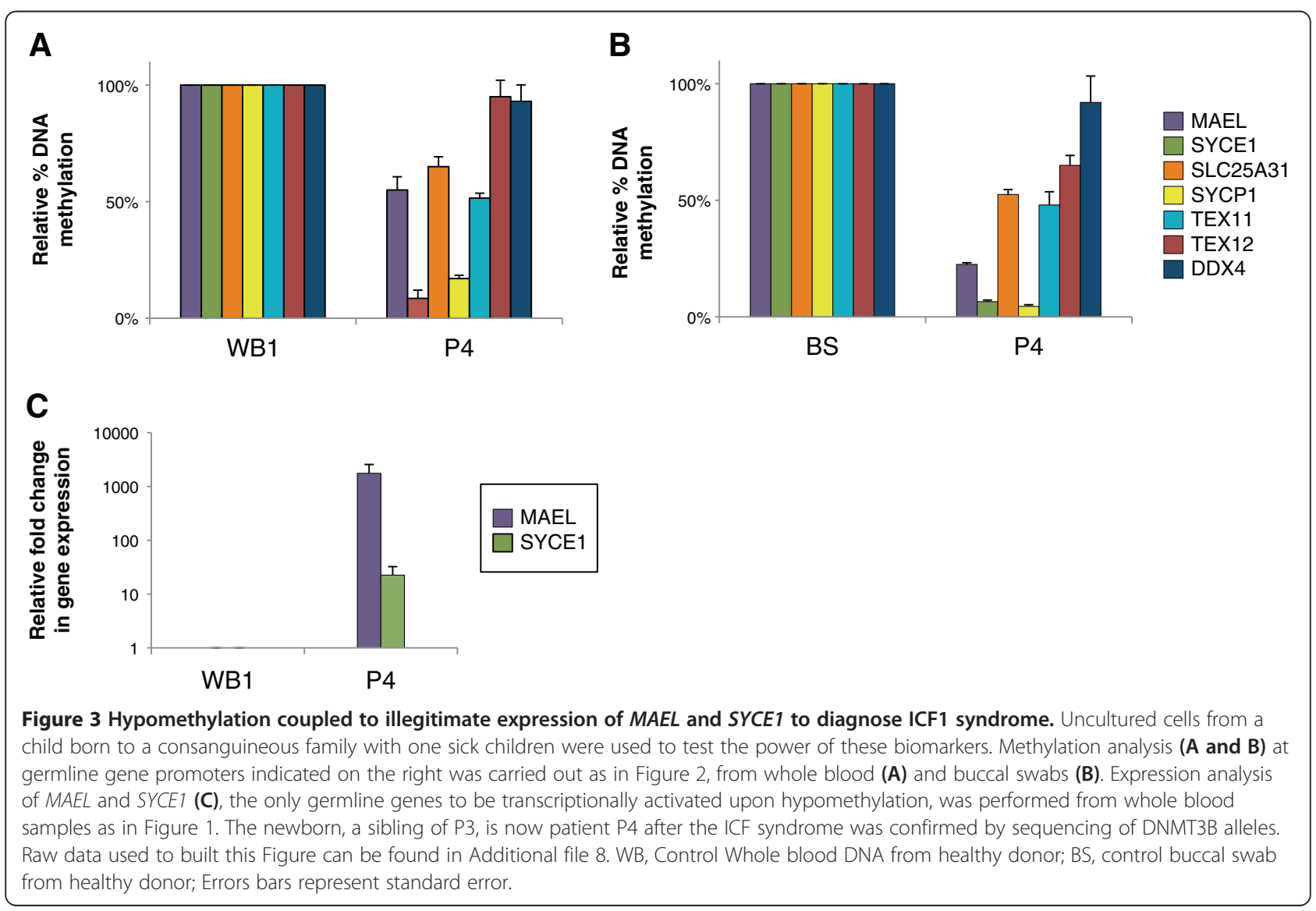


screening in cases where performing exome-sequencing or cytogenetics analysis may represent a challenge or when ICF should be suspected like in patients with immunodeficiency as the presenting factor if associated with facial anomalies [33], in patients that present an incomplete ICF phenotype or individuals from consanguineous families [25], or newborns from families where ICF cases have already been reported (this study). In addition, our analysis allowed the identification of unprecedented molecular characteristics in two ICF patients, suggestive of a novel type of genetic origin for the disease, stressing the need to continue the search for mutations that lead to immunodeficiency associated with chromosomal instability. The hallmark of ICF being hypomethylation of heterochromatin DNA repeats, combined, these efforts will have great impact on our understanding of the DNA methylation pathways.

\section{Additional files}

Additional file 1: Additional methods section for DNA methylation and gene expression analysis. Table of primers used for PCR amplification. Additional file 2: Table summarizing genetic mutations found in ICF patients already described and associated references.

Additional file 3: Table showing immunological characteristics of newly identified ICF patients.

Additional file 4: Southern blot analysis of DNA methylation at centromeric and juxta-centromeric regions of ICF patients.

Additional file 5: Germline genes expression and promoter methylation in control conditions including control fibroblasts as somatic cells, human testes and a cell line treated by the demethylating agent 5-azacytidine.

Additional file 6: Raw PCR data used to built expression histograms shown in Figure 1, and statistical analysis to compare healthy controls and ICF patients.

Additional file 7: (A) Additional information on expression analysis performed in cultured cells from patients, EBV-transformed lymphocytes or immortalized fibroblasts, suggesting that these cellular systems cannot provide reliable molecular markers for a disease with methylation defects. (B) Expression analysis and DNA methylation of germ line genes in lymphoblastoid cell lines from patients. (C) Expression analysis and DNA methylation of germ line genes in immortalized fibroblasts from patients.

Additional file 8: Raw PCR data used to built DNA methylation histograms shown in Figure 2, and statistical analysis to compare healthy controls and ICF patients.

Additional file 9: Control experiment showing that expression of Maelstrom decreases with the number of passages in culture.

Additional file 10: DNA methylation analysis at TEX12 and DDX4 promoters showing that their dependency on DNMT3B for methylation and silencing in murine cells is not conserved in humans.

\section{Competing interests}

The authors declare that they have no competing interest.

\section{Authors' contributions}

GV, ELW and SH carried out the molecular genetic studies. DS carried out the immunological characterization of newly enrolled ICF patients. HN, IY, HS carried out the exome sequencing of ICFX patients. FF, AM, CP collected the biological samples from ICF patients. GV and CF designed the study. GV coordinated the sample and data collection and analyzed the data. GV and
ELW drafted the manuscript. CF supervised the study and revised the manuscript. All authors read and approved the final manuscript.

\section{Acknowledgements}

The authors wish to thank all patients and family members for their participation in this study. We are grateful to Evani Viegas-Péquignot and Fabienne Nigon for assistance with registries and tissue collections collected in the frame of the previous "ICF consortium", and to Florent Hubé for critical reading of the manuscript. This work was supported by ANR (Agence Nationale pour la Recherche; ANR-09-GENO-035); ELW was supported by the French Ministry of Research and Ligue Nationale Contre le Cancer.

\section{Author details}

'Université Paris Diderot-Paris7, CNRS UMR7216, Epigénétique et Destin Cellulaire, Case Courrier 7042; 35, rue Hélène Brion, 75205 Paris, France. ${ }^{2}$ Center for the Study of Primary Immunodeficiencies, Assistance Publique-Hôpitaux de Paris, Necker Hospital, Paris, France. ${ }^{3}$ Institut National de la Santé et de la Recherche Médicale, Laboratory of Human Genetics of Infectious Diseases, Necker Branch, U980 Paris, France. ${ }^{4}$ Imagine Institute, University Paris Descartes, Sorbonne Paris Cité, Paris, France. ${ }^{5}$ Division of Epigenomics and Development, Department of Molecular Genetics, Medical Institute of Bioregulation, Kyushu University, Fukuoka, Japan. ${ }^{6}$ Service d'Hémato-oncologie Pédiatrique et Transplantations Médullaires, Centre Hospitalier Universitaire de Nancy, Hôpital Brabois Enfants, Vandœuvre-lès-Nancy, France. ${ }^{7}$ Unité de Génétique Médicale et laboratoire associé, INSERM UMR S_910, Faculté de Médecine, Université Saint Joseph, Beirut, Lebanon.

Received: 7 February 2014 Accepted: 11 April 2014

Published: 17 April 2014

\section{References}

1. Maraschio P, Zuffardi O, Dalla Fior T, Tiepolo L: Immunodeficiency, centromeric heterochromatin instability of chromosomes 1, 9, and 16, and facial anomalies: the ICF syndrome. J Med Genet 1988, 25:173-180.

2. Hagleitner MM, Lankester A, Maraschio P, Hulten M, Fryns JP, Schuetz C, Gimelli G, Davies EG, Gennery A, Belohradsky BH, de Groot R, Gerritsen EJ, Mattina T, Howard PJ, Fasth A, Reisli I, Furthner D, Slatter MA, Cant AJ, Cazzola G, van Dijken PJ, van Deuren M, de Greef JC, van der Maarel SM, Weemaes CM: Clinical spectrum of immunodeficiency, centromeric instability and facial dysmorphism (ICF syndrome). J Med Genet 2008, 45:93-99.

3. Ehrlich M, Jackson $\mathrm{K}$, Weemaes $\mathrm{C}$ : Immunodeficiency, centromeric region instability, facial anomalies syndrome (ICF). Orphan J Rare Dis 2006, 1:2.

4. Xu GL, Bestor TH, Bourc'his D, Hsieh CL, Tommerup N, Bugge M, Hulten M, Qu X, Russo JJ, Viegas-Pequignot E: Chromosome instability and immunodeficiency syndrome caused by mutations in a DNA methyltransferase gene. Nature 1999, 402:187-191.

5. Hansen RS, Wijmenga C, Luo P, Stanek AM, Canfield TK, Weemaes CM, Gartler SM: The DNMT3B DNA methyltransferase gene is mutated in the ICF immunodeficiency syndrome. Proc Natl Acad Sci U S A 1999, 96:14412-14417.

6. Okano M, Bell DW, Haber DA, Li E: DNA methyltransferases Dnmt3a and Dnmt3b are essential for de novo methylation and mammalian development. Cell 1999, 99:247-257.

7. Gowher $\mathrm{H}$, Jeltsch A: Molecular enzymology of the catalytic domains of the Dnmt3a and Dnmt3b DNA methyltransferases. J Biol Chem 2002, 277:20409-20414.

8. Moarefi AH, Chedin F: ICF syndrome mutations cause a broad spectrum of biochemical defects in DNMT3B-mediated de novo DNA methylation. J Mol Biol 2011, 409:758-772.

9. Ehrlich M: The ICF syndrome, a DNA methyltransferase $3 B$ deficiency and immunodeficiency disease. Clin Immunol 2003, 109:17-28.

10. de Greef JC, Wang J, Balog J, den Dunnen JT, Frants RR, Straasheijm KR, Aytekin C, van der Burg M, Duprez L, Ferster A, Gennery AR, Gimelli G, Reisli I, Schuetz C, Schulz A, Smeets DF, Sznajer Y, Wijmenga C, van Eggermond MC, van Ostaijen-Ten Dam MM, Lankester AC, van Tol MJ, van den Elsen PJ, Weemaes CM, van der Maarel SM: Mutations in ZBTB24 are associated with immunodeficiency, centromeric instability, and facial anomalies syndrome type 2. Am J Hum Genet 2011, 88:796-804. 
11. Weemaes CM, van Tol MJ, Wang J, van Ostaijen-Ten Dam MM, van Eggermond MC, Thijssen PE, Aytekin C, Brunetti-Pierri N, van der Burg M, Graham Davies E, Ferster A, Furthner D, Gimelli G, Gennery A, Kloeckener-Gruissem B, Meyn S, Powell C, Reisli I, Schuetz C, Schulz A, Shugar A, van den Elsen PJ, van der Maarel SM: Heterogeneous clinical presentation in ICF syndrome: correlation with underlying gene defects. Eur J Hum Genet 2013, 21:1219-1225.

12. Jiang $Y L$, Rigolet M, Bourc'his D, Nigon F, Bokesoy I, Fryns JP, Hulten M, Jonveaux P, Maraschio P, Megarbane A, Moncla A, Viegas-Péquignot E: DNMT3B mutations and DNA methylation defect define two types of ICF syndrome. Hum Mutat 2005, 25:56-63.

13. Tiepolo L, Maraschio P, Gimelli G, Cuoco C, Gargani GF, Romano C: Multibranched chromosomes 1, 9, and 16 in a patient with combined $\operatorname{IgA}$ and IgE deficiency. Hum Genet 1979, 51:127-137.

14. Tuck-Muller CM, Narayan A, Tsien F, Smeets DF, Sawyer J, Fiala ES, Sohn OS, Ehrlich M: DNA hypomethylation and unusual chromosome instability in cell lines from ICF syndrome patients. Cytogenet Cell Genet 2000, 89:121-128.

15. Ehrlich M, Buchanan $K L$, Tsien F, Jiang G, Sun B, Uicker W, Weemaes CM, Smeets D, Sperling K, Belohradsky BH, Tommerup N, Misek DE, Rouillard JM, Kuick R, Hanash SM: DNA methyltransferase 3B mutations linked to the ICF syndrome cause dysregulation of lymphogenesis genes. Hum Mol Genet 2001, 10:2917-2931.

16. Jin B, Tao Q, Peng J, Soo HM, Wu W, Ying J, Fields CR, Delmas AL, Liu X, Qiu J, Robertson KD: DNA methyltransferase 3B (DNMT3B) mutations in ICF syndrome lead to altered epigenetic modifications and aberrant expression of genes regulating development, neurogenesis and immune function. Hum Mol Genet 2008, 17:690-709.

17. Heyn H, Vidal E, Sayols S, Sanchez-Mut JV, Moran S, Medina I, Sandoval J, Simo-Riudalbas L, Szczesna K, Huertas D, Gatto S, Matarazzo MR, Dopazo J, Esteller M: Whole-genome bisulfite DNA sequencing of a DNMT3B mutant patient. Epigenetics 2012, 7:542-550.

18. Matarazzo MR, Boyle S, D'Esposito M, Bickmore WA: Chromosome territory reorganization in a human disease with altered DNA methylation. Proc Natl Acad Sci U S A 2007, 104:16546-16551.

19. Jefferson A, Colella S, Moralli D, Wilson N, Yusuf M, Gimelli G, Ragoussis J, Volpi EV: Altered intra-nuclear organisation of heterochromatin and genes in ICF syndrome. PLoS One 2010, 5:e11364.

20. Yehezkel S, Segev Y, Viegas-Pequignot E, Skorecki K, Selig S: Hypomethylation of subtelomeric regions in ICF syndrome is associated with abnormally short telomeres and enhanced transcription from telomeric regions. Hum Mol Genet 2008, 17:2776-2789.

21. Gatto S, Della Ragione F, Cimmino A, Strazzullo M, Fabbri M, Mutarelli M, Ferraro L, Weisz A, D'Esposito M, Matarazzo MR: Epigenetic alteration of microRNAs in DNMT3B-mutated patients of ICF syndrome. Epigenetics 2010, 5:427-443.

22. Lana E, Megarbane A, Tourriere H, Sarda P, Lefranc G, Claustres M, De Sario A: DNA replication is altered in Immunodeficiency Centromeric instability Facial anomalies (ICF) cells carrying DNMT3B mutations. Eur J Hum Genet 2012, 20:1044-1050.

23. Velasco G, Hube F, Rollin J, Neuillet D, Philippe C, Bouzinba-Segard $H$, Galvani A, Viegas-Pequignot E, Francastel C: Dnmt3b recruitment through E2F6 transcriptional repressor mediates germ-line gene silencing in murine somatic tissues. Proc Natl Acad Sci U S A 2010, 107:9281-9286.

24. Walton EL, Francastel C, Velasco G: Maintenance of DNA methylation: Dnmt3b joins the dance. Epigenetics 2011, 6:1373-1377.

25. Brun ME, Lana E, Rivals I, Lefranc G, Sarda P, Claustres M, Megarbane A, De Sario A: Heterochromatic genes undergo epigenetic changes and escape silencing in immunodeficiency, centromeric instability, facial anomalies (ICF) syndrome. PLoS One 2011, 6:e19464.

26. Rigolet M, Gregoire A, Lefort G, Blanchet P, Courbes C, Rodiere M, Sarda P Viegas-Pequignot E: Early prenatal diagnosis of ICF syndrome by mutation detection. Prenat Diagn 2007, 27:1075-1078.

27. Nitta H, Unoki M, Ichiyanagi K, Kosho T, Shigemura T, Takahashi H, Velasco G, Francastel C, Picard C, Kubota T, Sasaki H: Three novel ZBTB24 mutations identified in Japanese and Cape Verdean type 2 ICF syndrome patients. J Hum Genet 2013, 58:455-460.

28. Maatouk DM, Kellam LD, Mann MR, Lei H, Li E, Bartolomei MS, Resnick JL: DNA methylation is a primary mechanism for silencing postmigratory primordial germ cell genes in both germ cell and somatic cell lineages. Development 2006, 133:3411-3418.
29. Antequera F, Boyes J, Bird A: High levels of de novo methylation and altered chromatin structure at CpG islands in cell lines. Cell 1990, 62:503-514.

30. Vilain A, Bernardino J, Gerbault-Seureau M, Vogt N, Niveleau A, Lefrancois D, Malfoy B, Dutrillaux B: DNA methylation and chromosome instability in lymphoblastoid cell lines. Cytogenet Cell Genet 2000, 90:93-101.

31. Miniou P, Jeanpierre M, Blanquet V, Sibella V, Bonneau D, Herbelin C, Fischer A, Niveleau A, Viegas-Pequignot $\mathrm{E}$ : Abnormal methylation pattern in constitutive and facultative (X inactive chromosome) heterochromatin of ICF patients. Hum Mol Genet 1994, 3:2093-2102.

32. Hansen RS, Stoger R, Wijmenga C, Stanek AM, Canfield TK, Luo P, Matarazzo MR, D'Esposito M, Feil R, Gimelli G, Weemaes CM, Laird CD, Gartler SM: Escape from gene silencing in ICF syndrome: evidence for advanced replication time as a major determinant. Hum Mol Genet 2000, 9:2575-2587.

33. Kaya N, Al-Muhsen S, Al-Saud B, Al-Bakheet A, Colak D, Al-Ghonaium A Al-Dhekri H, Al-Mousa H, Arnaout R, Al-Owain M, lqbal M: ICF syndrome in Saudi Arabia: immunological, cytogenetic and molecular analysis. J Clin Immunol 2011, 31:245-252.

doi:10.1186/1750-1172-9-56

Cite this article as: Velasco et al:: Germline genes hypomethylation and expression define a molecular signature in peripheral blood of ICF patients: implications for diagnosis and etiology. Orphanet Journal of Rare Diseases 2014 9:56.

\section{Submit your next manuscript to BioMed Central and take full advantage of:}

- Convenient online submission

- Thorough peer review

- No space constraints or color figure charges

- Immediate publication on acceptance

- Inclusion in PubMed, CAS, Scopus and Google Scholar

- Research which is freely available for redistribution 